\title{
ПЕРСПЕКТИВЫ ГК ГАЗПРОМ НА ГАЗОВОМ РЫНКЕ ВЕНГРИИ
}

\author{
(c) 2021 Пилипенко Сергей Викторович \\ студент 2 курса Института магистратуры \\ Санкт-Петербургский государственный экономический университет, Россия, Санкт-Петербург \\ (c) 2021 Кузнецов Роман Сергеевич \\ студент 2 курса Института магистратуры \\ Санкт-Петербургский государственный экономический университет, Россия, Санкт-Петербург \\ (c) 2021 Тихонова Майя Владимировна \\ кандидат экономических наук, доцент \\ E-mail:mvt515@mail.ru
}

В данной статье проанализирован ресурсный потенциал Венгрии, в том числе геологическая модель местности, включающая в себя месторождения, динамику добычи и потребления природного газа. На основе анализа газового портфеля, динамики экспорта и импорта газа и основных игроков выявлена характеристика структуры энергетического рынка Венгрии (анализ проведён на основании источников за 2019 год). Предложен прогноз объемов поставок газа из России в Венгрию через Украину на девять месяцев 2021 года.

Ключевые слова: Венгрия, Россия, партнёрство, газовый рынок, международная торговля газом, прогноз поставок, трубопроводный газ, конкурентные преимущества.

Данная тема наиболее актуальна в эпоху диверсификации газовых поставок на европейском рынке, ведь для России рынок Европы является основным покупателем и долгосрочным надёжным партнёром. Однако каждая страна Европы стремится сократить свою зависимость от российского газа и попробовать себя в роли газового хаба, занимаясь поиском альтернативных поставщиков трубопроводного газа и альтернативных энергоресурсов, к примеру СПГ (сжиженный природный газ).

Гипотеза. Укрепление взаимоотношений между Россией и Венгрией способствует увеличению поставок российского газа на газовый рынок Венгрии.

Методы. Основной целью статьи является анализ текущего состояния газового рынка Венгрии и торговых отношений ГК Газпром и Венгрии. Для этого были использованы аддитивная и мультипликативная модели прогнозирования временных рядов с учётом сезонности, которые составляются при помощи парного регрессионного анализа и модификации коэффициента сезонности. Результатами прогнозирования является положительная динамика роста поставок газа, который поступает в Венгрию транзитом через Украину. Также были сформулированы основные конкурентные преимущества России как поставщика для газового рынка Венгрии, с учетом которых авторами предложена оценка роста или снижения экспорта российского газа в Венгрию в ближайший период.

Результаты и обсуждение. В связи со снижением добычи собственных энергоресурсов, Европейский союз компенсирует необходимое сырьё путём импорта. Ежегодно наблюдается рост импорта газа на внутренний рынок Европейского союза, что отображено на рисунке 1 [12].

По данным ООО «Газпром экспорт», крупнейшим импортёром российского газа на рынке Восточной и Центральной Европы стала Венгрия [4].

Мы считаем, что данная тема наиболее актуальна в эпоху диверсификации газовых поставок на европейском рынке, ведь для России рынок Европы является основным покупателем, с которым партнёрство ведется уже долгое время. Каждая страна Европы стремится сократить свою зависимость от российского газа, хочет попробовать себя в роли газового хаба, занимаясь поиском альтернативных поставщиков.

По нашему мнению, основная проблема заключается в том, что определённые страны стараются полностью отказаться от закупок трубопроводного газа из России, также они намереваются зарабатывать на этом, осуществляя услуги транзита. Основные задачи исследования: 


\section{ИМПОРТ ГАЗА СТРАНАМИ ЕС В ПЕРИОД С 2015-2020 ГОД, МЛН $\mathbf{M}^{\wedge} 3$}

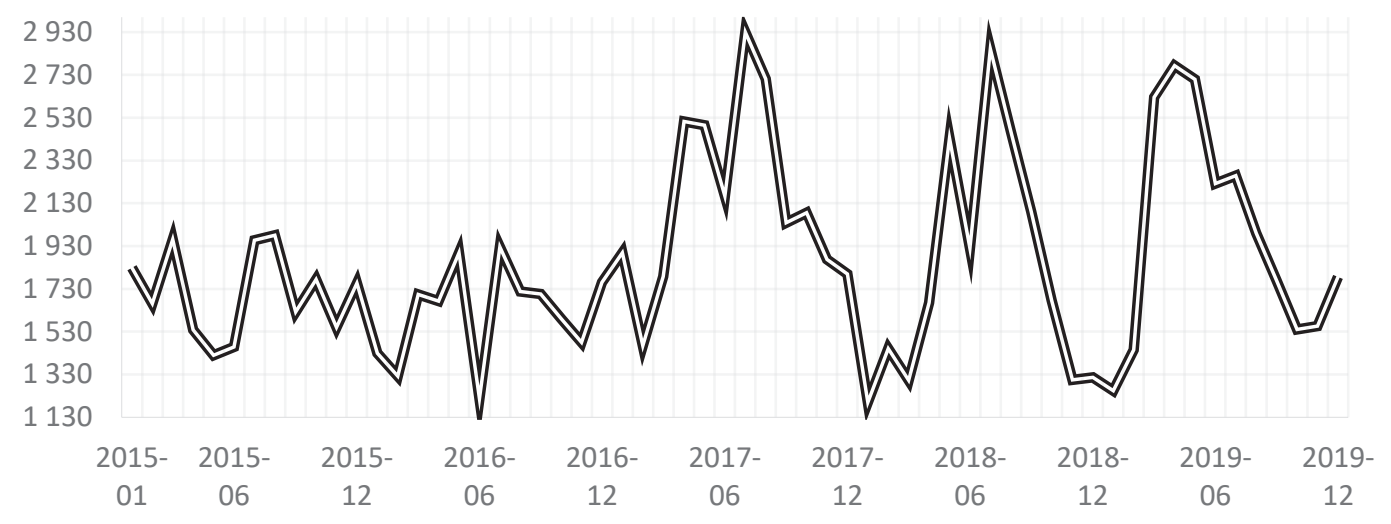

Рисунок 1. Импорт газа странами ЕС, млн. м $^{3}$

- определить характерные черты и основных игроков газового рынка Венгрии;

- особенности экспорта и импорта энергоресурсов в Венгрии;

- роли России в газовом портфеле Венгрии;

- составить прогноз поставок российского газа.

Для выполнения задач нам необходимо рассмотреть ресурсный потенциал Венгрии, для этого будет изучена геология газового рынка Венгрии; структуру энергетического рынка, для этого будет проанализирован газовый портфель страны; основных поставщиков энергоресурсов и основных покупателей.

Газовый рынок Венгрии берет начало в провинции бассейна реки Паннон представляет собой сложную в структурном отношении область, окруженную восточными Альпами, западными Карпатами, Муньи-Апушены, внешними Карпатами, южными Карпатами и складчатыми поясами Динарских Альп. Наиболее перспективные возобновляемые месторождения находятся в пределах Кёссенских сланцев Триасового периода, группы Нижнего Мецсека Юрского периода и нижних олигоценовых сланцев.

Геологическая модель группы Нижнего Мецсека Юрского периода предусматривает, что газ, добываемый из углей и углеродистых сланцев, перемещается, образуя плотно залегающие газовые залежи [5].

На рисунке 2 изображена динамика добычи природного газа в Венгрии, анализируя которую, можно проследить отрицательную тенденцию к добыче газа [13].

Запасы природного газа, которые добываются в стране, содержат низкое количество серы, что довольно сильно облегчает его использование и переработку. Однако добываемый газ отличается весьма неравномерной теплотворной способностью, которая колеблется в зависимости от его месторождения и составляет от 2,5 до 11 тыс. ккал/м ${ }^{3}$.

\section{Добыча природного газа в Венгрии, bm³}

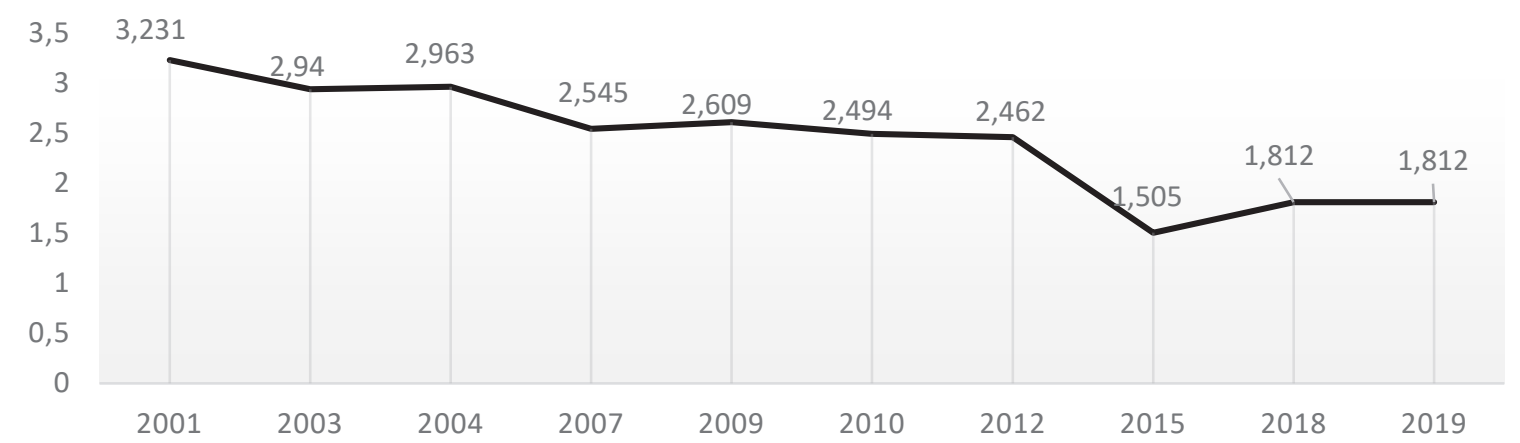

Рисунок 2. Добыча природного газа в Венгрии 
В последние годы годовое потребление природного газа в Венгрии постепенно снижается. В 2010 г. оно составляло 11,4 млрд. м $^{3}$, а в 2019 г. снизилось до 10 млрд. ${ }^{3}$, что прослеживается на рисунке 3 [7].

На наш взгляд, основной причиной является сокращение выработки электроэнергии из природного газа и снижение потребления населением, это объясняется тем, что большая часть природного газа используется для отопления, потребление которого является сезонным.

Другая причина заключается в том, что энергоэффективные методы (например, теплоизоляция) становятся все более распространенными, а отопительный период из-за изменения климата становится все короче и короче. Энергетическая безопасность и диверсификация источников стали приоритетными задачами как внутри страны, так и в ЕС.
Венгерский сектор торговли природным газом либерализован, группа MVM остается доминирующим игроком с долей рынка 60\%. Правительство с 2013 начало снижать цены для конечных пользователей, чтобы повысить спрос. В первый год цены были снижены на $10 \%$, а затем на 25\% в течение двух последующих лет [9]. На рисунке 4 представлен внутренний спрос на газ в процентном соотношении по отраслям [15].

В существующей структуре крупнейшим потребителем являются домохозяйства, которые имеют долю потребления в 40\%, 12\% - центральное теплоснабжения, показатель может вырасти за счёт увеличения газовой генерации электроэнергии. Доля промышленности и коммунальной сферы вместе составляет 26\%. 21\% составляют частные котельные и сельское хозяйство.

Экспорт газа из Венгрии представлен на рисунке 5 [16].

\section{Потребление природного газа в Венгрии, bm³}

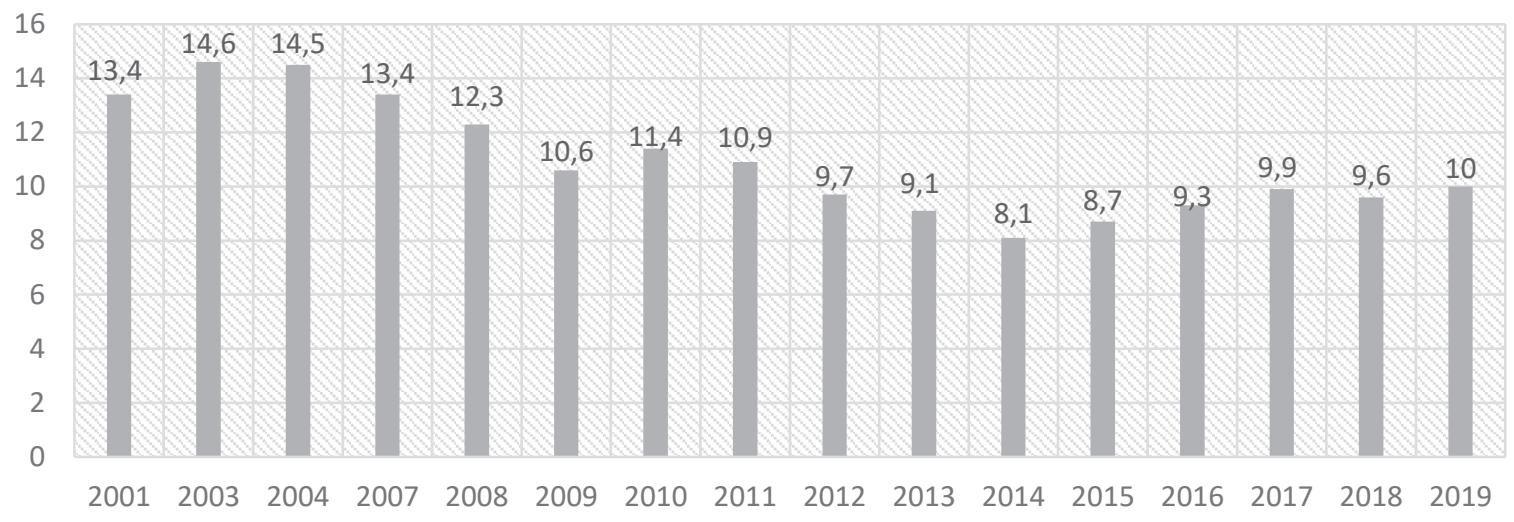

Рисунок 3. Потребление природного газа в Венгрии

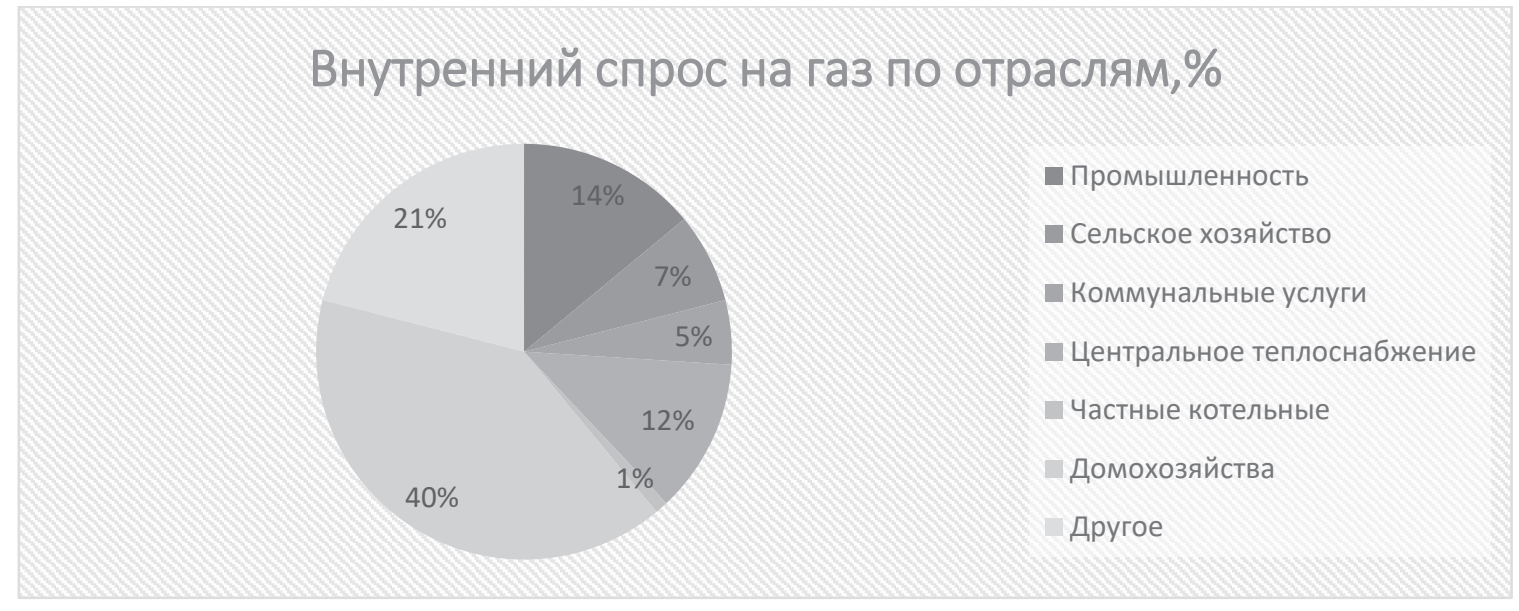

Рисунок 4. Внутренний спрос на газ по отраслям в Венгрии 


\section{Экспорт газа из Венгрии, \%}

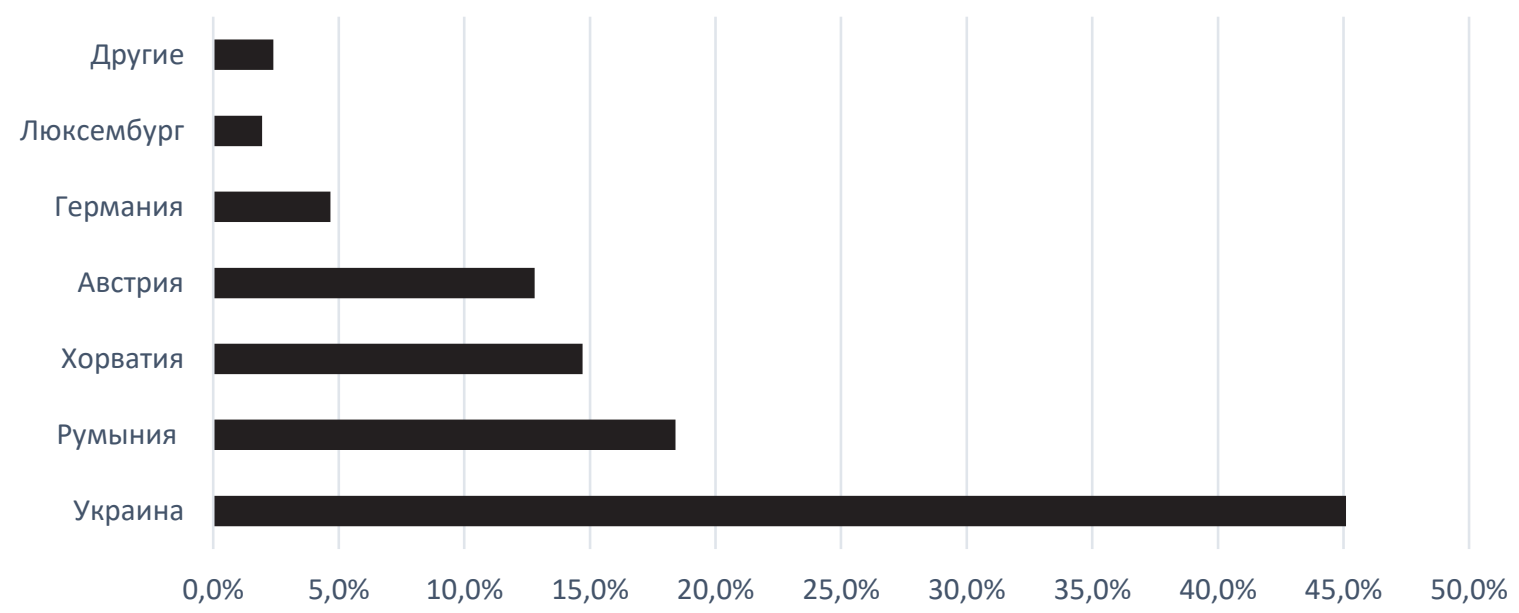

Рисунок 5. Экспорт газа из Венгрии

Венгрия в 2024 году увеличит мощность своего соединителя природного газа в направлении Словакии до более 5 миллиардов кубометров в год.

Мы считаем, что расширение станет актуальным, когда вторая нитка газопровода «Турецкий поток» будет введена в эксплуатацию. Этот газопровод является продолжением морского газопровода, по которому российский газ транспортируется в Турцию и вскоре будет поступать в Европу через Балканы. Венгрия находится на маршруте газопровода Россия-Австрия, и при увеличении пропускной способности сможет поставлять газ в Словакию [11].

На газ в корзине импортируемых полезных ископаемых приходится 31\%, в которых Россия имеет долю в 59\% (рисунок 6) [17].

Министр иностранных дел и торговли Венгрии Питер Сииярто подчеркнул, что сотрудничество с Россией очень важно для Венгрии с точки зрения внешней торговки и энергетической безопасности. 7 июня 2019 года между Венгрией и Россией было заключено соглашение на поставку газа в 2020 году, вслед за этим импорт российского газа вырос на $22 \%$ по сравнению с 2018 годом, за 11 месяцев 2019 года «Газпром» экспортировал в Венгрию порядка 9,3 млрд. м $^{3}$ газа [14].

Также министр заявил, что последующие переговоры будут сосредоточены на поставках газа в 2021 году и в дальнейшем периоде. И поставки российского газа по газопроводу «Турецкий поток», который предназначен для обхода Украины, могут начаться уже в конце 2021 или в начале 2022 года [10].

В связи с необходимостью диверсификацией источников поставок, которых должно быть не менее двух, Венгрия попросила США о помощи в добыче газа на румынском участке Чёрного моря, что может стать альтернативой россий-

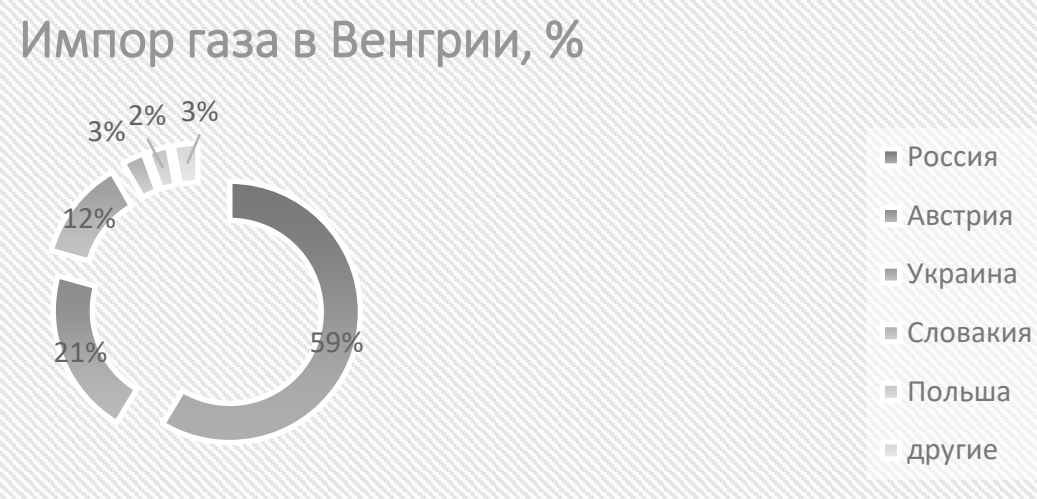

Рисунок 6. Импорт природного газа в Венгрии 
скому газу [2].

Будапешт также рассматривает возможность импорта СПГ через Хорватию, начиная с января 2021 года [11].

Исследовав газовый рынок страны и проанализировав взаимоотношения Венгрии и России, было принято решение спрогнозировать при помощи моделей временных рядов: мультипликативной и аддитивной модели,- поставки российского газа на будущие 9 месяцев на украинско-венгерскую границу.

Поставки российского газа в Венгрию осуществляются через территорию Украины, поэтому для анализа были взяты ежемесячные данные поставок газа из Украины в Венгрию (вместе с транзитным объёмом) в период с марта 2015 года и по декабрь 2020 [8], на основании этих данных была построена мультипликатив- ная и аддитивная модель, результатами которой стали прогнозные значения поставок в млн. м $^{3}$ на следующие 9 месяцев.

\section{1. Мультипликативная модель}

На рисунке 7 можно проследить положительную тенденцию ряда, также заметны сезонные колебания, вызвано это снижением внутреннего спроса на газ. Прогнозные значения имеют линию тренда с более крутым положительным наклоном, что объясняет стремление Венгрии продолжать и улучшать сотрудничество с Россией и компанией «Газпром экспорт» [14].

В таблице 1 представлены числовые прогнозные значения.

\section{2. Аддитивная модель}

На рисунке 8 отображены фактические и прогнозные значения поставок российского газа в Венгрию, рассчитанные по аддитивной модели.

\section{Поставки природного газа в Венгрию}

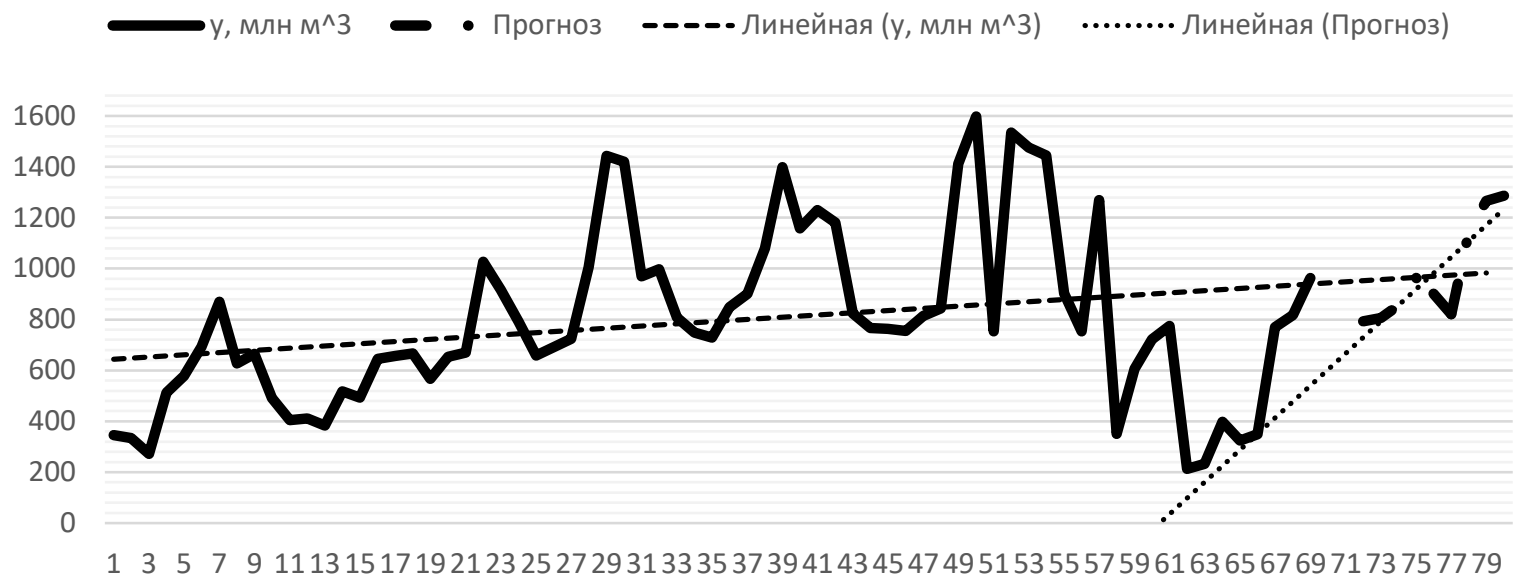

Рисунок 7. Фактические и прогнозные значения поставок газа из России в Венгрию через Украину (мультипликативная модель) Источник: составлено автором

Таблица 1. Прогнозные значения поставок газа из России в Венгрию через Украину (мультипликативная модель)

\begin{tabular}{|c|c|}
\hline Период & ${\text { Объём поставок, млн. } \mathbf{~}^{\mathbf{3}}}$ \\
\hline 01.2021 & 793,01 \\
\hline 02.2021 & 806,13 \\
\hline 03.2021 & 854,56 \\
\hline 04.2021 & 964,65 \\
\hline 05.2021 & 901,26 \\
\hline 06.2021 & 821,31 \\
\hline 07.2021 & 1142,70 \\
\hline 08.2021 & 1265,76 \\
\hline 09.2021 & 1286,56 \\
\hline
\end{tabular}

Источник: составлено автором 


\section{Поставки природного газа в Венгрию}

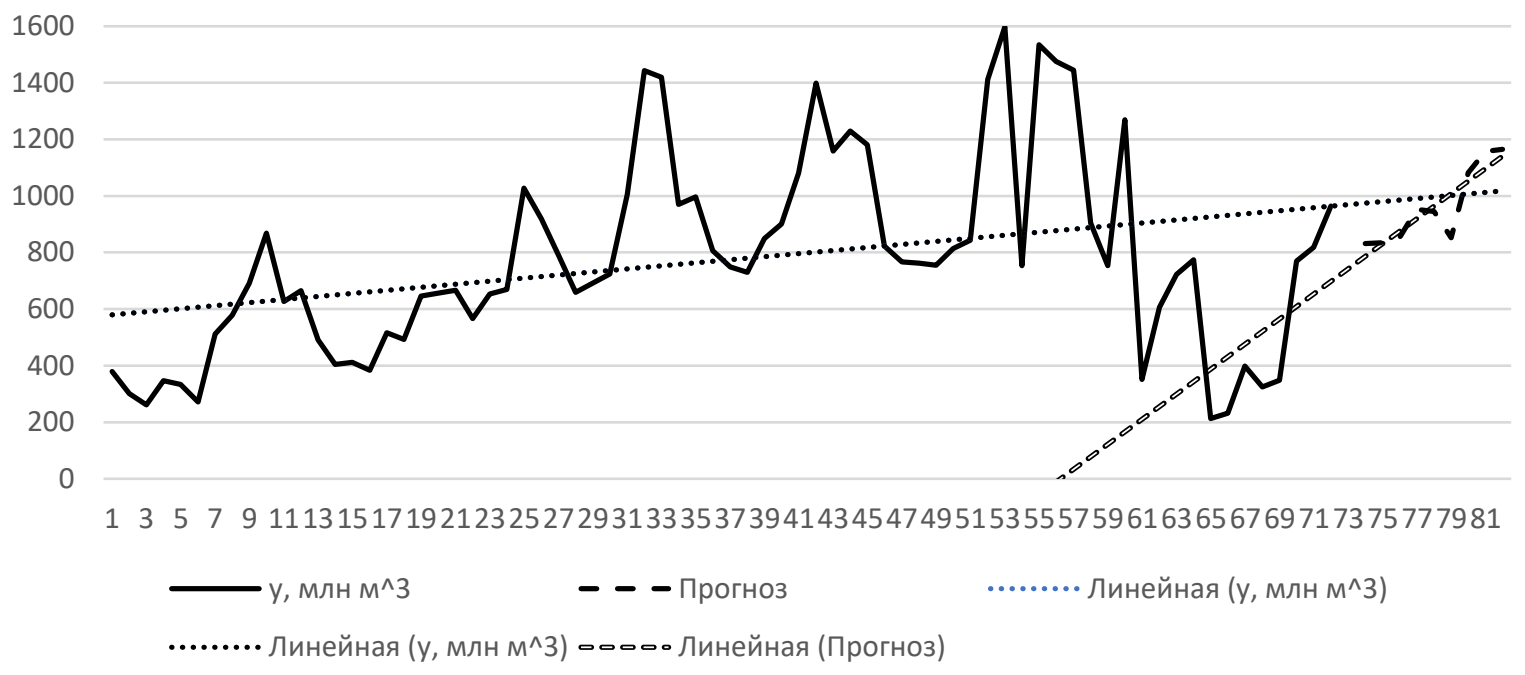

Рисунок 8. Фактические и прогнозные значения поставок газа из России в Венгрию через Украину (аддитивная модель)

Источник: составлено автором

В сравнении с мультипликативной моделью можно заметить незначительные различия в прогнозе, теперь наблюдается более пологий положительный наклон линии линейного тренда. В таблице 2 представлены числовые прогнозные значения.

Таким образом, сравнивая прогнозные значения двух моделей, наблюдаются незначительные отклонения, обусловленные величиной сезонной вариации.

Также был проведён точечный (рисунок 9) и интервальный прогноз поставок на период до начала поставок российского газа по газопроводу «Турецкий поток» в конце 2021- начале 2022 года, проведённый на основе данных ежегодных поставок газа из России в Венгрию ПАО «Газпром» [3].

Точечный прогноз заключается в получение прогнозного значения у, которое получается путём подстановки в уравнение регрессии прогнозного значения $\underline{\mathrm{x}}$.

Интервальный прогноз является доверительным интервалом самого прогноза, он содержит точную величину для прогнозного значения у с заданной вероятностью.

На рисунке 9 наблюдается совпадение линий линейного тренда фактических и прогнозных значений, они обе имеют отрицательный наклон, что говорит об уменьшении поставок, вероятнее всего, вследствие диверсификации источников поставок газа.

Дополнительно был проведён прогноз на 2021 год с использованием полиномиального тренда, который показал более оптимистичный результат. Точечный (линейный и полиномиальный) и интервальный прогноз представлены в таблице 3.

Таблица 2. Прогнозные значения поставок газа из России в Венгрию через Украину (аддитивная модель)

\begin{tabular}{|c|c|}
\hline Период & Объем поставок, млн. м3 \\
\hline 01.2021 & 831,64 \\
\hline 02.2021 & 835,00 \\
\hline 03.2021 & 852,62 \\
\hline 04.2021 & 952,25 \\
\hline 05.2021 & 944,83 \\
\hline 06.2021 & 851,67 \\
\hline 07.2021 & 1081,65 \\
\hline 08.2021 & 1157,41 \\
\hline 09.2021 & 1164,96 \\
\hline
\end{tabular}

Источник: составлено автором 


\section{Точечный прогноз поставок газа в Венгрию}

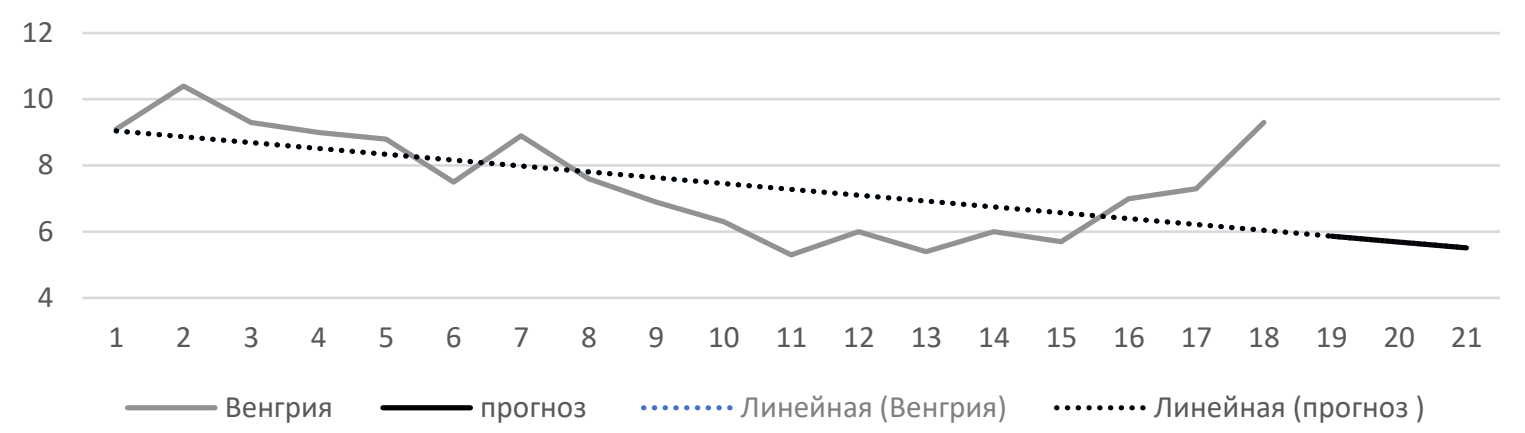

Рисунок 9. Точечный линейный прогноз поставок российского газа в Венгрию Источник: составлено автором

Таблица 3. Точечные и интервальные значения прогноза поставок газа из России в Венгрию в период 2020-2022 года, млрд. м3

\begin{tabular}{|c|c|c|c|}
\hline \multirow{3}{*}{2020} & Точечный прогноз & \multicolumn{2}{|c|}{ Интервальный прогноз } \\
\hline & \multirow{2}{*}{5,8656} & нижняя граница & верхняя граница \\
\hline & & 2,780872136 & 8,950327864 \\
\hline \multirow{3}{*}{2021} & Точечный прогноз & Интер & огноз \\
\hline & \multirow{2}{*}{5,6889} & нижняя граница & верхняя граница \\
\hline & & 2,727064533 & 8,650735467 \\
\hline \multirow{3}{*}{2022} & Точечный прогноз & Интер & огноз \\
\hline & \multirow{2}{*}{5,5123} & нижняя граница & верхняя граница \\
\hline & & 2,660413889 & 8,364186111 \\
\hline \multirow{3}{*}{2021} & Точ. прогноз (парабола) & Интерваль & (парабола) \\
\hline & \multirow{2}{*}{9,1116} & нижняя граница & верхняя граница \\
\hline & & 7,252000552 & 10,97119945 \\
\hline
\end{tabular}

Источник: составлено автором

Таким образом, точечные значения входят в интервальные значения.

По итогам проведенного исследования можно сделать выводы, которые отражены в таблице 4, где была составлена оценка Венгрии по определённым критериям, позволяющим оценить перспективу роста или снижения экспорта российского газа.

Основные конкурентные преимущества России для Венгрии [1]:

- Надёжность партнёрских отношений;

- Наличие выгодных долгосрочных контрактов;

- Стабильность поставок несмотря на затруднения с транзитом через Украину;

- Россия обеспечивает порядка 50\% потребностей Венгрии в газе.
Таким образом, обобщая характеристики рынка Венгрии, с учетом зарубежных конкурентов, с использованием прогнозирования на основе аддитивной/мультипликативной моделей на следующие месяцы можно сделать вывод, что, учитывая имеющиеся долгосрочные партнерские отношения с Россией, подкрепленные международными контрактами, на рынке Венгрии произойдёт диверсификация поставок в связи с указанием EC, однако разрывать партнёрские отношения с Россией партнёр не намерен. Все основные задачи исследования были выполнены:

- были определены характерные черты, основные поставщики и покупатели энергоресурсов газового рынка Венгрии;

- были рассмотрены особенности импорта 
Таблица 4. Оценка роста/снижения экспорта российского газа в Венгрию

\begin{tabular}{|c|c|}
\hline Критерии оценки & Венгрия \\
\hline Наличие долгосрочных контрактов & + \\
\hline Политическая поддержка & + \\
\hline Наличие судебных разбирательств & - \\
\hline Наличие альтернативных поставок & \\
\hline Затруднение поставок в связи с транзитом через Украину & + \\
\hline Рост/снижение экспорта в перспективе на 5 лет & + \\
\hline
\end{tabular}

Источник: составлено автором

и экспорта энергоресурсов в Венгрии;

- была определена роль России в газовом портфеле Венгрии, в результате были выявлены конкурентные преимущества России для газового рынка Венгрии;
- был составлен прогноз поставок российского газа через Украину в Венгрию при помощи мультипликативной и аддитивной моделей временных рядов, учитывающих сезонность.

\section{Библиографический список}

1. Венгрия намерена увеличить поставки газа из России./ NEFTEGAZ [Электронный ресурс] - Режим доступа: https://neftegaz.ru/news/Trading/536902-vengriya-namerena-uvelichit-postavki-gaza-iz-rossii/ (дата обращения: 06.06.2020);

2. Венгрия попросила США о помощи в добыче газа./Агентство нефтегазовой информации [Электронный ресурс] - Режим доступа: http://angi.ru/news/2871529-Венгрия-попросила-США-о-помощи-в-добыче-газа/ (дата обращения: 06.06.2020);

3. Годовой отчёт./ ПАО Газпром - официальный сайт [Электронный ресурс] - Режим доступа: https://www. gazprom.ru/investors/disclosure/reports/2018/ (дата обращения: 04.06.2020);

4. Динамика реализации газа в Европу/ OОО «Газпром экспорт» - официальный сайт [Электронный ресурс] Режим доступа: http://www.gazpromexport.ru/statistics/ (дата обращения: 02.05.2020);

5. Оценка возобновляемых ресурсов нефти и газа в провинции бассейна реки Паннон, Венгрия/ Christopher J. Schenk, Timothy R. Klett, Phuong A. Le, Michael E. Brownfield, and Heidi M.Leathers-Miller/The USGS Energy Resources Program [Электронный ресурс] - Режим доступа: https://pubs.usgs.gov/fs/2017/3033/fs20173033. pdf (дата обращения: 06.06.2020);

6. Транспортировка./ ООО «Газпром экспорт» - официальный сайт [Электронный ресурс] - Режим доступа: http://www.gazpromexport.ru/projects/transportation/ (дата обращения: 14.05.2020);

7. BP Statistical Review of World Energy/BP [Электронный ресурс] - Режим доступа: https://www.bp.com/ content/dam/bp/business-sites/en/global/corporate/pdfs/energy-economics/statistical-review/bp-statsreview-2019-natural-gas.pdf (дата обращения: 06.06.2020);

8. Export GTF IEA-2./IEA [Электронный ресурс] - Режим доступа: https://www.iea.org/reports/gas-trade-flows https://iea.blob.core.windows.net/assets/5c49dd8e-39a1-401c-ab22-e4891004e8a6/Export_GTF_IEA.xls (дата обращения: 04.06.2020); 
9. Hungary country brief./Austrian Government - official website [Электронный ресурс] - Режим доступа: https:// www.dfat.gov.au/geo/hungary/Pages/hungary-country-brief (дата обращения: 02.05.2020);

10. Hungary gas supplies guaranteed for this year, says Foreign Minister after Russia meeting./NEFTEGAZ [Электронный ресурс] - Режим доступа: https://neftegaz.ru/en/news/energy/537175-hungary-gas-supplies-guaranteedfor-this-year-says-foreign-minister-after-russia-meeting/ (дата обращения: 03.05.2020);

11. Hungary to boost capacity of gas pipeline to Slovakia./Kallanishenergy [Электронный ресурс] - Режим доступа: https://www.kallanishenergy.com/2020/06/03/hungary-to-boost-capacity-of-gas-pipeline-to-slovakia/ (дата обращения: 06.06.2020);

12. Imports-gas-monthly data./Eurostat-official website [Электронный ресурс] - Режим доступа: https://ec.europa. eu/eurostat/databrowser/view/NRG_124M_custom_597728/default/line?lang=en (дата обращения: 01.02.2021).

13. Natural gas - Production/Index Mundi [Электронный ресурс] - Режим доступа: https://www.indexmundi.com/ g/g.aspx?v=136\&c=hu\&l=en (дата обращения: 06.06.2020);

14. Russian gas imports further growing in Hungary/ПАО Газпром - официальный сайт. [Электронный ресурс] - Режим доступа: https://www.gazprom.com/press/news/2019/october/article490429/ (дата обращения: 03.05.2020);

15. SECAP SUSTAINABLE ENERGY AND CLIMATE ACTION PLAN FENNTARTHATÓ ENERGIA ÉS KLÍMA AKCIÓTERV/ SECAP [Электронный ресурс] - Режим доступа: https://docplayer.hu/108693719-Secap-sustainable-energyand-climate-action-plan-fenntarthato-energia-es-klima-akcioterv-szolnok-megyei-jogu-varos.html (дата обращения: 06.06.2020);

16. Where does Hungary export Gas to?/OEC-официальный сайт [Электронный ресурс] - Режим доступа: https:// oec.world/en/profile/country/hun/ (дата обращения: 06.06.2020);

17. Where does Hungary import Petroleum Gas from?/ ОЕС-официальный сайт [Электронный ресурс] - Peжим доступа: https://oec.world/en/visualize/tree_map/hs92/import/hun/show/52711/2019/ (дата обращения: 02.05.2020). 